\title{
Speaker Design in the Context of Southern American English: Process Models and Empirical Evidence ${ }^{1}$
}

\begin{abstract}
Current 'Speaker Design' approaches to sociolinguistic variation investigate how speakers may pro-actively deploy the linguistic resources (variation) at their disposal to achieve certain communicative effects. In this paper, Speaker Design is investigated in the case of Southern American English, a regional variety that can reportedly be used specifically by women to project personal charm. An interactional as well as a cognitive sociolinguistic account of this process are provided. Furthermore, empirical evidence for its workings is presented. This evidence is derived from a speaker evaluation experiment, whose results are outlined. It is argued that this experiment demonstrates that Southern American English elicits certain social associations in listeners such that women using it sound socially attractive. Female Southern speakers can tap into this effect to contextualize their utterances accordingly, giving rise to communicative effects such as 'charming' customers into buying products.
\end{abstract}

Key words

Cognitive sociolinguistics; style-shifting; Speaker Design; Southern American English; contextualization

\section{Introduction}

The present paper is a case study of how, or, more precisely, by which interactional and cognitive mechanisms speakers of Southern American English, particularly women, may deploy their regional variety in order to achieve certain communicative outcomes such as, in a sales context, charming customers into buying products. Below, I begin by locating my undertaking in the realm of so- 
called Speaker Design approaches to sociolinguistic variation (see SchillingEstes 2002), which specifically focus on the agentive use of language varieties for strategic, rhetorical purposes. I then explicate how interactional sociolinguistic conceptualizations of conversational contextualization (Gumperz 1982) are particularly suited for capturing the communicative processes underlying Speaker Design. As current research in the area of cognitive sociolinguistics has proposed further modeling of these processes from a perception perspective, I then present a respective cognitive model of contextualization in the example of a token in Southern American English. Subsequent to this, I adduce empirical evidence for the workings of the outlined mechanisms by drawing on well-established methodology of language attitude research, namely, a speaker evaluation experiment testing Southern vs. mainstream American English. As the experimental outcome shows, the evaluative profile elicited by the use of Southern American English features a salient pattern by which women's usage calls up certain positive social associations in American listeners. It is these associations that female Southern speakers can then in turn 'tap into' during interactional meaning-making - viz. meaning-making by Speaker Design.

\section{Background: The Speaker Design approach to stylistic variation}

In a seminal review that traces the evolution of the sociolinguistic study of stylistic variation - or, the study of variation within the language use of individual speakers, as contrasted with variation across social groups - Schilling-Estes (2002) identifies three approaches that have dominated the field since around the 1960s. Thus, the earliest studies, initiated by William Labov (e.g. 1966, 1972), conceptualized stylistic variation largely as a function of how much attention speakers paid to their own speech, with less attention (less self-consciousness, less formality) correlating with more vernacular production, and more attention with increased orientation towards prestigious forms of language. While such research successfully established the inherent systematicity of vernacular speech, as well as the close interconnection between intra-speaker (individual) and inter-speaker (between-group) variation, its projections about the workings of sociolinguistic styles as a rather automated fallout of typically uni-dimensional situational factors have been open to criticism. This criticism can in fact also be extended to subsequent 'Audience Design' approaches to stylistic variation (Bell 1984, 2001), which hold that speakers shift their linguistic styles not (only) as a function of attention to speech or formality of a situation, but in response to a reference group of (present or absent) audience members / addressees. As Schilling-Estes (2002) points out, traditional conceptualizations of style-shifting as a responsive phenomenon are in general not easily married with present-day social constructivist views on human interaction as an agentive, online process in which social life is being created just as much as reflected. To do full justice to the latter in variationist research, what needs to be taken into account is 'Speaker 
Design', or the ways in which speakers are found to use linguistic variation proactively, rather than only re-actively and automatically, for communicative, rhetorical purposes such as projecting and negotiating identities and relationships in interaction.

In this line, then, much current state-of-the-art research on sociolinguistic styles has taken on a Speaker Design perspective, investigating, for example, how adolescents in a Detroit high school deploy linguistic variables in subtly differentiated ways to project 'jock' and 'burnout' identities and affiliations (Eckert 2000); how two interactants from a rural tri-ethnic community in North Carolina use variation in rhoticity and realizations of /ai/ to (re-)shape their ethnic identities in the course of an interview (Schilling-Estes 2004); how a British pantomime performer employs features ranging from RP to South Wales Valleys English to construct diverse on-stage personas (Coupland 2007); or how speakers of Austrian German deploy shifts from standard into dialect to achieve antagonistic participant alignments in political discussions (Soukup 2009).

As the notion of Speaker Design proposes to relate to a fundamental principle of language use (its agentiveness and goal-directedness), it is in fact only to be expected that instantiations of the phenomenon can be found in relation to virtually any identifiable linguistic variety. (Indeed, as Johnstone (1999: 519) put it, "The idea that linguistic choices can serve rhetorical purposes has a history of several centuries"; adding that "[this] idea has been rediscovered by sociolinguists several times".) Regarding Southern American English (i.e., the regionally characteristic type/s of English spoken in the southern United States), ${ }^{2}$ which serves as my case in point in this paper, Speaker Design has been documented for example in Johnstone's (1999) study of Texas women's language use, where 'sounding like a Southern Belle' turned out to be considered "particularly useful as part of a sexually-charged manipulative strategy" (Johnstone 1999: 514). Thus, in one of the cases described, a female Texan sales representative called Terri King is quoted as saying, "My Southern drawl makes me $\$ 70,000$ a year!" King reports that she deploys her regional accent strategically when selling mailing lists over the telephone: "It's hilarious how these businessmen turn to gravy when they hear it. I get some of the rudest, most callous men on the phone, and I start talkin' to them in a mellow Southern drawl, I slow their heart rate down and I can sell them a list in a heartbeat" (Johnstone 1999: 505). ${ }^{3}$ A number of very similar anecdotes were related to me all throughout my own field work on Southern American English in the U.S., conducted in 1999. The most notable example came from a professor at a Tennessee university who reported that his daughter uses her Southern accent very successfully to sell jewelry in a store in Connecticut (thus, in the northern United States) - some customers were said to enter the store merely to hear her talk. My contact jokingly called such strategic use of Southern American English 'country-boying', adding that women were actually much better at it than men. 


\section{Theorizing Speaker Design from an interactional perspective}

As obvious as it may seem to state that speakers deploy the sociolinguistic resources (variants and varieties) they have in their repertoire as communicative means and to communicative ends, and as this notion is being applied in the exegesis of more and more variationist data, the mechanics underlying the process require further specification. From an 'interactional sociolinguistic' perspective, then, which straddles the agendas of anthropological linguistics, sociology of language, and conversational discourse analysis (see e.g. Gumperz 2001, Schiffrin 1994, Tannen 2004), the strategic deployment of sociolinguistic styles can be conceptualized in terms of a 'contextualization cue', or a cue that indexes (points to, activates, highlights) certain aspects of interactional context as relevant for locally situated meaning-making (conversational 'inferencing' - Gumperz 1982). ${ }^{4}$ Thus, a speaker's use of a specific style indexes ( $=$ 'contextualizes' the utterance in terms of) the social meanings commonly associated with that style, drawing these meanings into the picture for utterance interpretation. In turn, listeners may retrieve the respective meanings as 'schematic knowledge' (see e.g. Widdowson 2004) from memory, to the point that they are available to them, and thus realize such a respective interpretation, viz. a respective communicative effect, from the set of information activated.

This contextualization process can in fact also be cast in terms of Bakhtin's ([1952-53] 1986) famous notion of the inherent 'dialogicality' of language, by which talking is understood as a dynamic process involving an active listener and a responsive speaker who co-determine each other: the speaker by anticipating a listener's response, and formulating his or her utterances accordingly, and the listener by taking a responsive stance to what s/he is hearing. In Bakhtin's own words,

When constructing my utterance, I try to actively determine [the listener's] response. Moreover, I try to act in accordance with the response I anticipate, so this anticipated response, in turn, exerts an active influence on my utterance [...] When speaking I always take into account the apperceptive background of the addressee's perception of my speech: the extent to which he is familiar with the situation, whether he has special knowledge of the given cultural area of communication, his views and convictions, his prejudices (from my viewpoint), his sympathies and antipathies - because all this will determine his active responsive understanding of my utterance. These considerations also determine my choice of a genre for my utterance, my choice of compositional devices, and, finally, my choice of language vehicles, that is, the style [sic!] of my utterance. (Bakhtin [1952-53] 1986: 95-96)

In that sense, the speaker may anticipate the social meanings (schematic knowledge) a listener will call up based on the talk produced, and manipulate the talk accordingly (stylistically), in view of a certain communicative outcome arising from respective contextualization. 


\section{Modeling Speaker Design from a cognitive sociolinguistic perspective}

While Speaker Design processes and effects can thus be quite helpfully theorized on an interactional level from the perspective of sociocultural discourse analysis, recent proposals in the realm of 'cognitive sociolinguistics' (a new interdisciplinary enterprise that marries variationist sociolinguistic with cognitive linguistic research - see e.g. Geeraerts et al. 2010) have further advanced the agenda by modeling contextualization phenomena on the order level of individual cognition, which has hitherto not been paid much attention to. Here, in particular, tribute is duly paid to the fact that the listener - his/her perception and interpretive inferencing - plays a decisive role in the realization of communicative effects by Speaker Design. Thus, Kristiansen (2008) conceptualizes the mechanism by which listeners associate linguistic styles with their schematic knowledge of respective social meanings in terms of a metonymic process. ${ }^{5}$ According to her framework, linguistic varieties can be conceived of as gestalt-like clusters of perceptually salient and contrastive linguistic features. These features, in turn, are the stored stereotypical ideals ('prototypes' - cf. e.g. Rosch 1975) of actual realizations. Constituted on the basis of our culturally relative experience and socialization, the systemic clusters of such features, which we can call 'varietygestalts', serve as 'cognitive reference points' in the on-line categorization of our sociolinguistic environment, and hence also in conversational inferencing.

Figure 1 instantiates the contextualization process as seen under Kristiansen's framework with a listener's perception of a token of the word time realized with monophthongization of the [ar] diphthong, a Southern shibboleth. ${ }^{6}$

Figure 1. A map of the cognitive contextualization process by which a perceived feature of Southern American English ([ar] monophthongization) is associated with respective social meanings (based on Kristiansen 2008)

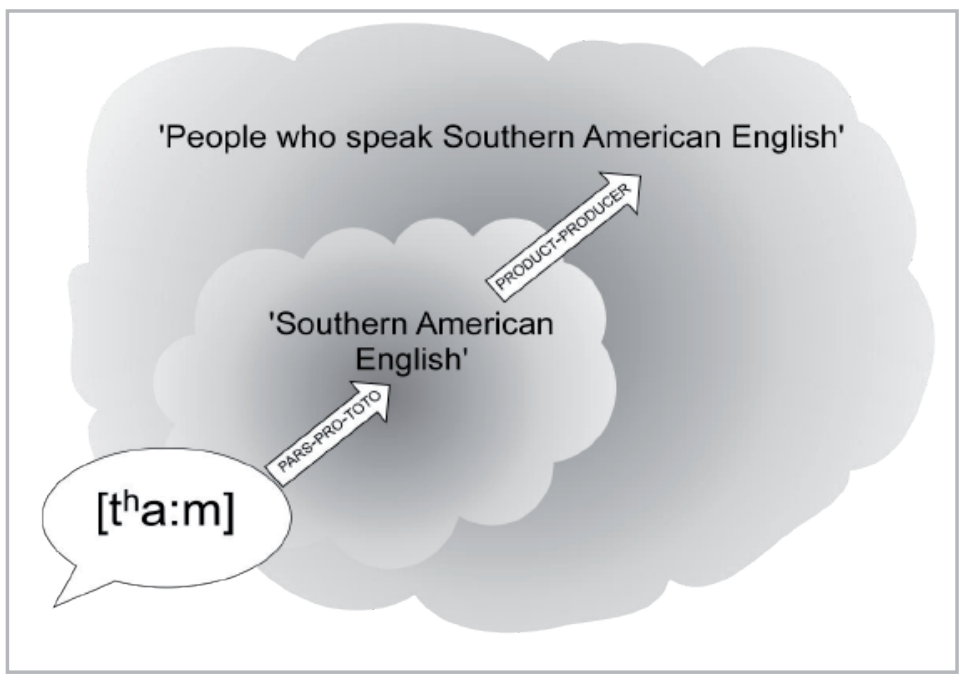


As Figure 1 illustrates, with the required schematic (cultural background) knowledge in place, the perception of monophthongized time may trigger the varietygestalt of 'Southern American English' in a listener, via a metonymic pars-prototo schema. (In the figure, the radial shading and cloud-like outline of the variety-gestalt 'Southern American English' are meant to express its fuzzy boundaries as well as its prototype-structure, in the sense that "some realizations will be more 'typical' or 'central' or 'better examples' of a given variety than others" Kristiansen 2008: 59.) The evoked variety, in turn, is metonymically related to a certain social group - 'People who speak Southern American English' - via a product-producer schema, and thus ultimately to the social meanings (evaluations, characterizations, stereotypes) associated with this group on the grounds of schematic cultural models (notice, again, the prototype-structure of the group, expressed in the radial shading and cloud form).

\section{Speaker Design effects: Adducing empirical evidence}

What we have seen so far, then, is that a Speaker Design approach to the study of sociolinguistic styles can be plausibly modeled from an interactional as well as a cognitive sociolinguistic perspective. As a next requisite step, however, it remains to be seen in how far the processes and their outcomes as just described can be traced empirically. In other words, what evidence can we adduce for the fact that the speaker-listener 'dialog' outlined here is likely to work, that listeners will indeed activate certain (which?) social meanings upon hearing somebody use a certain linguistic variety, so that these are brought into the mix for utterance interpretation? Or, in short, how can Terri King be so sure that her Southern accent actually boosts her income?

One way to put this to the test is to experimentally simulate situations in which listeners are exposed to different styles in juxtaposition and to simultaneously elicit their ad hoc social associations. This, incidentally, is exactly what the field of language attitude study within the social psychology of language has been doing for the past five decades, under the heading of 'speaker evaluation' experiments, a methodology launched with Lambert et al.'s (1960) study on attitudes towards different varieties of French and English in Canada.

Speaker evaluation experiments typically present informants with speaker samples in which the content is held constant but the speaking style varies in one way or another. Informants are then asked to rate each speaker on multipoint semantic differential scales featuring adjectives such as 'friendly' or 'educated'. Subsequent statistical analysis establishes any significant differences in the scores received by each speaker, which, as other variables are controlled as much as possible, can be attributed to the variable of style.

The method has been criticized particularly from a social constructivist and discourse analytic perspective, as its quantitative nature is said to suppress meaningful nuances and variability in responses, and to treat the elicited language 
attitudes as positivist entities fixed in informants' minds, rather than as emergent products of a contextually situated construction (elicitation) process (see Hyrkstedt and Kalaja 1998; Potter and Wetherell 1987). However, it can be argued that for the specific purpose of garnering evidence regarding interactional contextualization, a large-scale elicitation precisely of general, commonly shared stereotypes, rather than of individually differentiated nuances of attitude, is in fact a desideratum. After all, frameworks like Gumperz's and Kristiansen's model stylistic contextualization as the activation of readily available, general, culturally established schemas. This is not to say, though, that the immediate situation in which the activation (and elicitation) of such schemas takes place is irrelevant for the outcome. From an interactional sociolinguistic perspective, any meaning-making activity is locally situated in an ongoing speech event, bearing the imprint of specific contextual parameters on different orders of granularity. In other words, which schemas (stereotypes, social evaluations, attitudes) exactly will be (able to be) activated via Speaker Design in a given conversation depends as much on the broader cultural context as on the immediate purpose and cast of an interaction.

But rather than precluding the use of (attitudinal) experimental methods for the elucidation of what goes on in such situated contextualization processes, as social constructivist criticism seems to imply (see above), this just means that the simulation itself needs to be conceptualized as a speech event, and its contextual parameters specifically matched with the ones of the particular interaction it is supposed to illuminate. This way, the meaning construction process (i.e. the appraisal of the different styles concerned) can be assumed to take place in a similarly configured frame for the listeners / informants, by virtue of which the outcomes and findings from both data sets should become sufficiently congruous from a constructivist perspective to warrant extrapolation.

In the following, then, I present an experiment dealing with attitudes towards Southern American English whose contextual configuration seems compatible with the type of sales pitch speech event anecdotally related by Johnstone (1999 - see above). ${ }^{7}$ I argue that, based on this compatibility, the experimental findings can be adduced to provide some concrete, empirical evidence for the workings of conversational contextualization in the given interactional situation - for how and why 'country-boying' works so well for Southern women like Terri King.

\section{The social meaning of Southern American English in the U.S.: Findings from a field study ${ }^{8}$}

The study on the social meanings of (or language attitudes towards) Southern American English in the USA which I report here consisted of a speaker evaluation experiment carried out with a total of 291 U.S. students (169 females, 122 males; aged 18-24) in 1999 (coincidentally, the year of Johnstone's report on Texas women's language use). Recruited at two universities each in the states of Tennessee and Vermont, my student informants represented the South $(\mathrm{N}=150)$ 
and the North (viz. New England, N=141) respectively, in order to include both an in- and out-group perspective. They were asked to listen to four different speakers: two with a 'mainstream' American accent (i.e. an accent that could not easily be regionally placed), and two with a Southern (i.e. Tennessee) accent, one male and one female each. All speakers were performing the same text, a oneminute general information piece about sales and salespeople. The informants were asked to rate each speaker in turn on five-point bipolar semantic differential scales (Osgood et al. 1957) for 21 adjective pairs (e.g. likeable - not likeable, educated - uneducated), which were provided in a questionnaire. The adjective list was compiled as a common denominator of two paradigms, namely qualities deemed necessary in a salesperson and common stereotypes about people from the American South (both derived from respective literature). The informants were furthermore asked to imagine their rating was part of a sales job application process the speakers were engaging in, thus additionally anchoring the experiment in a sales context.

Results for this study were computed using the statistical software package SPSS, with the central focus on comparing the speakers' mean scores on the adjective scales. As a first step, a factor analysis was conducted, in order to identify which adjective items were related in the sense of showing a similar patterning of scores. ${ }^{9}$ As it turned out, three factor groups (patterns) could be extracted ${ }^{10}$ :

(1) A 'competence' factor that grouped the items sharp-slow, successful-not successful, determined-wavering, educated-uneducated, leadership qualities-no leadership qualities, intelligent-not intelligent, ambitious-not ambitious, industrious-lazy, self-confident-not self-confident

(2) A 'personal integrity' factor that grouped the items honest-dishonest, trustworthy-not trustworthy, polite-impolite, good manners-bad manners, reliable-unreliable, likeable-not likeable, helpful-not helpful, open-minded-not open-minded

(3) A 'social attractiveness' factor that grouped the items outgoing-shy, sense of humor-no sense of humor, sociable-unsociable, friendly-unfriendly

Subsequent one-way repeated-measures Analyses of Variance (ANOVAs) ${ }^{11}$ established that the assessment patterns underlying these groupings of items were essentially as follows: for the competence items, the Southern speakers consistently scored significantly lower than the mainstream speakers. For personal integrity, the ratings were fairly similar across the board. But for social attractiveness, the Southern female speaker significantly outscored all others. Table 1 provides the results of repeated-measures ANOVAs comparing the speakers' mean scores along the three factors identified above. 
Table 1. Results from repeated-measures ANOVAs comparing the four speakers' mean scores $(\overline{\mathrm{x}})$ for each of the three factor groups

\begin{tabular}{|c|c|c|c|c|c|c|c|}
\hline $\begin{array}{l}\text { Speaker // } \\
\text { Factor group }\end{array}$ & $\operatorname{MsF}(\overline{\mathbf{x}})$ & SoF $(\overline{\mathbf{x}})$ & 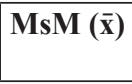 & SoM $(\overline{\mathbf{x}})$ & $\mathbf{n}$ & $\mathbf{F}$ & \begin{tabular}{|l|} 
Effect size \\
$\left(\right.$ partial $\left.\eta^{2}\right)$
\end{tabular} \\
\hline 'Competence' & $3.77^{\mathrm{b}}$ & $3.33^{\mathrm{c}}$ & $3.94^{\mathrm{a}}$ & $2.99^{\mathrm{d}}$ & 290 & 120.692* & .295 \\
\hline 'Personal integrity' & $3.78^{\mathrm{a}}$ & $3.73^{\mathrm{a}}$ & $3.75^{\mathrm{a}}$ & $3.58^{\mathrm{b}}$ & 290 & $7.141^{*}$ & .024 \\
\hline $\begin{array}{l}\text { 'Social } \\
\text { attractiveness' }\end{array}$ & $3.38^{\mathrm{b}}$ & $3.97^{\mathrm{a}}$ & $3.50^{\mathrm{b}}$ & $3.39^{\mathrm{b}}$ & 290 & $41.089 *$ & .124 \\
\hline
\end{tabular}

* indicates statistical significance as found in the repeated measures ANOVAs $(p<0.001)$

Different letters designate statistically different means as found in post-hoc related $t$ tests $(\mathrm{p}<0.05)$; same superscripts designate homogeneous groups (i.e. no significant difference found)

As Table 1 shows, for competence (comprising traits such as sharp, intelligent, and educated) the male 'mainstream' speaker (MsM) has the highest score, followed by his female counterpart (MsF), and then by the female Southern (SoF) and the male Southern speaker (SoM). All differences are statistically significant. The effect size (explanatory value of the variable 'speaker') can be considered large (partial $\eta^{2}=.295$; see e.g. Coolican 2009 for reference), which means that the changing of speakers explains a big part of the differences in scores. As for personal integrity (comprising i.a. honest and polite), the male Southern speaker

Figure 2. Visualization of the results from repeated-measures ANOVAs comparing the four speakers' mean scores for each of the three factor groups

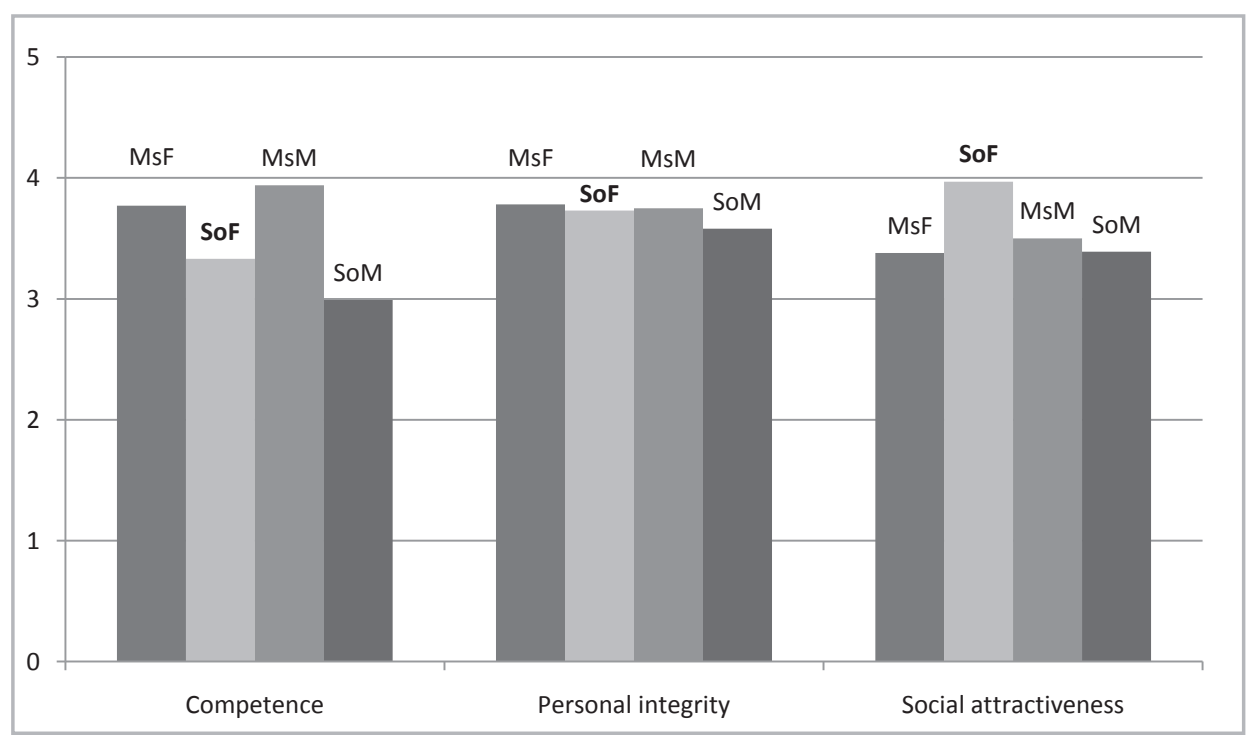


scores lower than all others; though here the effect is in fact small, and the results are thus rather inconclusive. Much more strikingly, because constituting once again a clear effect, the Southern female significantly outscores all other speakers on social attractiveness, which was measured by the items outgoing, sense of humor, sociable, and friendly. The scores for the other speakers did not differ significantly here, so that she clearly sticks out. Figure 2 is a visualization of these results which additionally dramatizes the salient patterning in the data.

Subsequent further statistical testing using 4x2 mixed-design ANOVAs investigated whether the variables of informants' gender and region of origin significantly affected the scoring on any of the individual adjective scales. For informants' gender, only small effects were found that showed a consistent tendency within the female sample to rate speakers higher, across the board. The explanatory power of this variable is therefore decidedly low. More was to be expected from the variable of informants' region of origin - after all, it could be hypothesized that the Tennessee informants would rate their peer speakers 'better', considering that these were using a language variety supposedly similar to the informants' own. This, however, was not borne out in the data at all. In fact, for the competence-related items, wherever ratings differed, the Tennessee informants consistently rated the Southern speakers lower than the informants from New England did. Results for items from the other two factor groups differed more rarely, inconclusively, and to low statistical effect.

In sum, then, this study points to the fact that, in a sales context, a Southern accent is clearly associated with low 'competence' in the sense of slowness of uptake, low intelligence, and little education; this, across the board - meaning, both for in-group and out-group informants, where the former are at times even 'harsher' on their peers than the latter. By contrast, a Southern accent can indeed function as a bonus when it comes to perceptions of social charm - but only when used by a woman. This finding was also reflected in some open comments informants provided in the questionnaire. Thus, $3 \%$ or eight of the informants volunteered, without being prompted, that Southern speech sounded considerably more charming in females than in males. As one person put it rather succinctly, "Southern women sound happy and perky."

\section{Discussion and conclusion(s)}

It has probably already become clear that the findings from the attitudinal experiment I have just reported integrate very well with the anecdotal data on Speaker Design using Southern American English which I presented further above. To recapitulate, I argued earlier that the attested agentive, rhetorical use of Southern speech styles to achieve certain communicative effects, like charming customers into buying goods, is best conceptualized along the lines of a contextualization process whereby the use of Southern American English metonymically evokes respective schematic social meanings in listeners, which a speaker can then tap 
into. I contend now that the above experiment provides cogent, empirical evidence for the following:

(1) Hearing features of Southern American English indeed activates social meanings in American listeners that are significantly distinct from the associations called up by a 'mainstream' variety of American English. When asked to produce ad-hoc judgments in immediate response to Southern and non-Southern speech samples, American informants provide systematically different evaluative profiles with high statistical probability.

(2) The social meanings associated with Southern American English include a salient gendered schema by which a Southern accent sounds particularly sociable and charming in women.

(3) The identified stereotypes are wide-spread and commonly shared in American culture (because shared across regions), so that they can be assumed to constitute reliable resources for strategic interactional contextualization.

(4) The fact that the attitudinal findings were elicited within the topical realm of salespeople and sales pitches ensures that the contextual frame within which my informants were engaging in the meaning-making activity of 'judging speakers during an experiment' is largely compatible with the frame in which, for example, Texas saleswoman Terri King's audience (her customers) engage in meaning-making during live conversation, when she is pitching her mailing lists to them on the phone. (Incidentally, in both cases - the experiment and the phone interaction - there is/was also no visual contact between listeners and speakers.) From a social constructivist perspective on human interaction, such compatibility now justifies the extrapolation of findings from the experiment to the everyday talk, furnishing a plausible explication of the ways in which a Southern accent can boost a saleswoman's record.

As I pointed out before, meaning-making is always locally situated and contingent upon the situational setting in which it occurs - whether the event be a conversation or an artificially created experiment. In this point, the present study may also serve as admonition and reminder to experimental scientists within or beyond sociolinguistics, that even supposedly 'controlled' activity is, intrinsically, contextually situated activity. Disregarding this fact may indeed lead down the path of undue generalization and essentializing of findings. Paying due tribute to this fact, however, and 'tailoring' experiments with an ulterior purpose of extrapolation in view, may lead to substantial evidence for the workings of cognitive processes in ongoing interaction, as I hope to have demonstrated here. In particular, as in the present case, such methodological integration can lend credibility and plausibility to exegeses of interactional data describing phenomena of sociolinguistic Speaker Design, as a fundamental meaning-making strategy in human interaction. 


\section{Notes}

1 I would like to cordially thank two anonymous reviewers for their comments, as well as Jan Chovanec for his editing and for welcoming me most warmly in Brno in 2010, upon a visit most kindly facilitated by Ludmila Urbanová.

2 For overviews and linguistic descriptions of Southern American English see e.g. Nagle and Sanders (2003).

3 Johnstone references Stevens (1996: E1) for this quote, which is taken from an interview conducted for a Texas newspaper.

4 See also Auer (1992: 4) for a respective definition of 'contextualization cue'.

$5 \quad$ Note that Gumperz (e.g. 1982) actually develops his notion of contextualization in step with his idea of 'metaphorical [sic!] code-switching'. However, because he consistently describes contextualization in terms of a 'signaling' of contextual aspects, a metonymic (indexical), rather than a metaphoric (iconic), relationship between features and social meanings, as proposed by Kristiansen, seems to be a better terminological fit from a cognitive sociolinguistic perspective.

$6 \quad$ For discussion of Southern American English phonology see e.g. Dorrill (2003).

7 It would be rewriting history to claim that the experiment was specifically configured to match this type of setting; rather, the fact that the experiment was outfitted with a compatible context constituted an instance of scientific serendipity. For an experiment deliberately tailored to specific discourse analytic purposes see Soukup (2009).

8 This study is reported in full detail in Soukup (2000).

9 Principal Component Analysis, using an eigenvalue of $>1$ as criterion of extraction (Kaiser's criterion) and varimax rotation. See e.g. Rietveld and van Hout (1993) for reference on factor analysis.

10 The labels for these groups were selected in analogy to a personality trait categorization established in Lambert (1967) and popular in language attitude research.

11 ANOVAs were not originally featured in the statistical analysis, but carried out for the purposes of the present paper. For reference on statistical procedure see e.g. Coolican (2009).

\section{References}

Auer, Peter (1992) 'Introduction: John Gumperz' approach to contextualization'. In: Auer, Peter and Aldo DiLuzio (eds.) The Contextualization of Language. Amsterdam: John Benjamins, 1-37.

Bakhtin, Mikhail ([1952-53] 1986) 'The problem of speech genres'. In: Emerson, Caryl and Michael Holquist (eds.) Speech Genres and Other Late Essays, transl. by Vern W. McGee. Austin: The University of Texas Press, 60-102.

Bell, Allan (1984) 'Language style as audience design'. Language in Society 13, 145-204.

Bell, Allan (2001) 'Back in style: Reworking audience design'. In: Rickford, John R. and Penelope Eckert (eds.) Style and Sociolinguistic Variation. Cambridge: Cambridge University Press, 139-169.

Coolican, Hugh (2009) Research Methods and Statistics in Psychology. $5^{\text {th }}$ ed. London: Hodder Education.

Coupland, Nikolas (2007) Style: Language Variation and Identity. New York: Cambridge University Press.

Dorrill, George (2003) 'The phonology of English in the South'. In: Nagle, Stephen J. and Sara L. Sanders (eds.) English in the Southern United States. New York: Cambridge University Press, 119-125.

Eckert, Penelope (2000) Linguistic Variation as Social Practice: The Linguistic Construction of Identity in Belten High. Oxford: Blackwell. 
Geeraerts, Dirk, Gitte Kristiansen and Yves Peirsman (eds.) (2010) Advances in Cognitive Sociolinguistics. Berlin: Walter de Gruyter.

Gumperz, John J. (1982) Discourse Strategies. Cambridge: Cambridge University Press.

Gumperz, John J. (2001) 'Interactional sociolinguistics: A personal perspective'. In: Schiffrin, Deborah, Deborah Tannen and Heidi E. Hamilton (eds.) The Handbook of Discourse Analysis. Malden: Blackwell, 215-228.

Hyrkstedt, Irene and Paula Kalaja (1998) 'Attitudes toward English and its functions in Finland: A discourse-analytic study’. World Englishes 17(3), 359-368.

Johnstone, Barbara (1999) 'Uses of Southern-sounding speech by contemporary Texas women'. Journal of Sociolinguistics 3(4), 505-522.

Kristiansen, Gitte (2008) 'Style-shifting and shifting styles: A socio-cognitive approach to lectal variation'. In: Kristiansen, Gitte and René Dirven (eds.) Cognitive Sociolinguistics. Berlin: de Gruyter, 45-88.

Labov, William (1966) The Social Stratification of English in New York City. Washington, DC: Center for Applied Linguistics.

Labov, William (1972) Sociolinguistic Patterns. Philadelphia: University of Pennsylvania Press.

Nagle, Stephen J. and Sara L. Sanders (eds.) (2003) English in the Southern United States. New York: Cambridge University Press.

Lambert, Wallace E. (1967) 'A social psychology of bilingualism'. Journal of Social Issues 23(2), 91-109.

Lambert, Wallace E., Richard Hodgson, Robert C. Gardner and Samuel Fillenbaum (1960) 'Evaluational reactions to spoken languages'. Journal of Abnormal and Social Psychology 60(1), 44-51.

Osgood, Charles E., George J. Suci and Percy H. Tannenbaum (1957) The Measurement of Meaning. Urbana: University of Illinois Press.

Potter, Jonathan and Margaret Wetherell (1987) Discourse and Social Psychology: Beyond Attitudes and Behaviour. London: Sage.

Rietveld, Toni and Roeland van Hout (1993) Statistical Techniques for the Study of Language and Language Behaviour. Berlin: Mouton de Gruyter.

Rosch, Eleanor (1975) 'Cognitive representations of semantic categories'. Journal of Experimental Psychology: General 104, 192-233.

Schiffrin, Deborah (1994) Approaches to Discourse. Malden: Blackwell.

Schilling-Estes, Natalie (2002) 'Investigating stylistic variation'. In: Chambers, J.K., Peter Trudgill and Natalie Schilling-Estes (eds.) The Handbook of Language Variation and Change. Malden: Blackwell, 375-401.

Schilling-Estes, Natalie (2004) 'Constructing ethnicity in interaction'. Journal of Sociolinguistics 8(2), 163-195.

Soukup, Barbara (2000) “'Y'all come back now, y'hear!?” Language attitudes in the United States towards Southern American English'. Mag. phil. Thesis, University of Vienna.

Soukup, Barbara (2009) Dialect Use as Interaction Strategy: A Sociolinguistic Study of Contextualization, Speech Perception, and Language Attitudes in Austria. Vienna: Braumüller.

Stevens, Liz (1996) 'It's the drawl, y'all'. Fort Worth Star-Telegram (May 25), El: 8.

Tannen, Deborah (2004) 'Interactional sociolinguistics / Interaktionale Soziolinguistik'. In: Ammon, Ulrich, Norbert Dittmar, Klaus J. Mattheier and Peter Trudgill (eds.) Sociolinguistics / Soziolinguistik, vol. 1, $2^{\text {nd }}$ ed. Berlin: de Gruyter, 76-88.

Widdowson, H.G. (2004) Text, Context, Pretext: Critical Issues in Discourse Analysis. Malden: Blackwell. 
Barbara Soukup currently researches and teaches at the University of Vienna. She obtained a $\mathrm{PhD}$ in linguistics from Georgetown University in Washington, DC, focusing on the interface of sociolinguistic variation study, social psychology of language, and interactional discourse analysis. Her book entitled Dialect Use as Interaction Strategy: A Sociolinguistic Study of Contextualization, Speech Perception, and Language Attitudes in Austria appeared in 2009 in the Series 'Austrian Studies in English' (Braumüller, Vienna).

Address: Dr. Barbara Soukup, Mag. phil., MSc, Department of English and American Studies, University of Vienna, Spitalgasse 2, Hof 8, A-1090 Vienna, Austria. [email: barbara.soukup@univie. ac.at] 